\title{
Analysis of Written English: The Case of Female University Students in Saudi Arabia
}

\author{
Islam Ababneh $^{1}$ \\ ${ }^{1}$ Department of Languages and Translation, Faculty of Education and Arts, University of Tabuk, Tabuk, Saudi Arabia \\ Correspondence: Islam Ababneh, Department of Languages and Translation, Faculty of Education and Arts, University \\ of Tabuk, Tabuk, Saudi Arabia.
}

Received: November 7, 2016

Accepted: January 3, $2017 \quad$ Available online: March 8, 2016

doi:10.11114/ijsss.v5i4.2264

URL: https://doi.org/10.11114/ijsss.v5i4.2264

\begin{abstract}
This research sheds some light on the difficulties faced by Saudi students when writing in the English language by examining specific writing errors committed by the students. Fifty female students in their fourth year of study at the University of Tabuk in the department of languages and translation who were enrolled in the subject of error analysis (a kind of linguistic analysis that emphasizes the errors learners make in a target language) were given a quiz to write approximately one page about each one of three topics: effects of social media on Saudi social life, Saudi marriage customs, and Saudi economy. The quiz was graded and the writing errors were classified into four main categories: grammatical, syntactic, substance, and lexical types following Hubbard et al. (1996) classifications of errors. Then, the number of errors in each category was counted and the corresponding frequency was calculated. The findings of this study show that most frequent types of errors made by the students were in the categories of grammar (tenses, singular/plural, articles), syntax (subject-verb agreement), and substance (spelling).
\end{abstract}

Keywords: error analysis, writing, Saudi students, essays

\section{Introduction}

Generally, writing is a difficult task for most people and it usually becomes more troubling to write in a second language. Arab native speaking students generally face problems in communicating in the English language and they have even more hardship in writing complete correct sentences and paragraphs. Therefore, an investigative study should look into the specific types of errors committed by Arab students in order to recommend suitable remedies in teaching fundamental English courses. Overall, writing is considered as intricate, complex, and is the most difficult of the language abilities to acquire (Allen \& Corder, 1974) and learners make various writing errors. Vahdatinejad (2008) maintains that error analyses can be used to determine what a learner needs to be taught and provides the necessary information about what is lacking in the learner's competence. (Dulay and Burt, 1973) suggested that errors are signs of students' development and they reflect the progress in writing and communication competence. (Al Buainain, 2007) testified that writing is dynamic, nonlinear and involves multiple processes. There are two major causes of errors: interlingual (interference from first language) and intralingual (the difficulty of the second language itself). (Dulay et al., 1982) explained that intralingual errors are similar to those made by children learning a target language as their first language while Interlingual errors are similar in structure to a semantically equivalent phrase or sentence in the learner's NL. According to (Ancker, 2000), errors occur for many reasons, for example, interference from the native language, overgeneralization, incomplete knowledge of the target language and the complexity of the target language itself. (Jarvis, 2002) explained that some of the systematicity in the errors that learners committed was attributed to discourse factors and some linguistic contexts. (Gass \& Selinker, 2001) defined errors as "red flags" that provide evidence of the learner's knowledge of the second language. (Corder, 1967) stated that there are two types of errors: performance errors and competence errors. The first are made when learners are tired or hurried. The second are more serious since they reflect inadequate learning. Burt and (Kiparsky, 1972) made a distinction between two types of errors: Global errors which hinder communication by causing confusion in the relationship between and among the parts of discourse such as " wrong word order in sentence" and Local errors such as the ones that "do not go beyond the clause or sentence level". (Taylor, 1975) explained that errors contain valuable information on the strategies that people use to acquire a language.

A number of papers about writing errors have also sprung up in the Arab world. (Al-Khuwaileh and Shoumali, 2000) 
stressed that English writing is essential for teaching English in Arab institutions of higher education where the medium of instruction is English. (Alkhresheh, 2010) revealed how Jordanian EFL learners committed a great number of syntactic interlingual errors; i.e. word order within some simple sentence structure, which he explained were due to the transfer of L1 habit. (Diab, 1996) performed an error analysis study of the interference of the mother-tongue, Arabic, in the English writings of EFL students at the American University of Beirut. Furthermore, (Farooq, 1998) analyzed both the transfer and overgeneralization error patterns in written texts of upper-basic Japanese learners, in an EFL context. (Habash, 1982) studied common proposition errors in the writings of UNRWA students and found out that majority of the errors were attributable to interference from the students' native language of Arabic. (Ridha, 2012) conducted a study on the writings of $80 \mathrm{EFL}$ college students and then categorized their writings errors into: grammatical, lexical/ semantic, mechanics, and word order types of errors. The study concluded that most of the errors were due to L1 (Arabic) transfer. In a study of school children, (AbiSamra, 2003) collected samples of written work from grade 9 students and then categorized the errors into grammatical (prepositions, articles, adjectives, etc.); syntactic (coordination, sentence structure, word order, etc.); lexical (word choice); semantic and substance (punctuation, capitalization, and spelling); and discourse errors. He found that one third of the students' committed errors were due to transfer from Arabic; many of the errors were semantics and vocabulary types and the highest numbers of errors were in the spelling, syntax and grammar types. This study will add to the literature in writing errors by focusing on a sample of university female students in one region of Saudi Arabia.

\section{Method}

A writing quiz that included three different topics was attempted by fifty female students in the second semester of the academic year 2015/2016. The students completed the quiz in three separate sessions with writing about one topic in each session. The students were given an ample time to write approximately one page (100 - 150 words) about each topic and they were encouraged to use all their familiar related vocabulary and phrases in writing about the following topics:

- Effects of social media on social life in Saudi Arabia

- Marriage customs in Saudi Arabia

- Saudi Arabia economy

The students were all female Saudi Arab natives in their early twenties who had public or private Saudi school education and at the time of conducting this research had joined the University of Tabuk English program in the department of languages and translation attempting to obtain a degree in English studies. The students were enrolled in a fourth year course called "error analysis" as a requirement of the English degree plan; error analysis is a kind of linguistic analysis that emphasizes the errors learners make in a target language. (Dulay et al., 1982) explained that error analysis is a technique that deals with almost all errors made by second language learners including those resulting from the first language learning and it provides an explanation for the many unexplained but frequently observed errors made by students. Almost all the students have only lived in the country of Saudi Arabia and had never resided in any foreign country except for short visits for tourism or when accompanying a family member on some business trips outside the country. The students verbally professed that they used mainly Arabic for communications at their homes and inside the university campus; and that they rarely utilized English except during short conversations with their class instructors. In short, the students came from similar socioeconomic and similar educational backgrounds.

After collecting all students' writings, a taxonomy of errors was constructed and then the errors were classified in an appropriate categories. The number of errors and the corresponding frequency was tabulated following (Hubbard et al., 1996, pp. 135-141) method of identifying and analyzing learners' errors where a taxonomy of the most common writing errors was constructed in (category/subcategory) format. Errors are not the same as mistakes; where according to (James, 1998) a mistake can be self-corrected, but errors are likely to occur repeatedly and can be recognized by a teacher but not by the learner. (Ellis, 1997) noted that errors reflect a gap in learner's knowledge, while mistakes reflect occasional lapses in performance. The errors were identified and classified into one or more of four categories: grammar, syntax, substance, or word choice.

\section{Results and Discussions}

In coding the data, the frequency (number of times each error was committed) was added; then a percentage of each error was obtained in relation to the overall number of errors. Table 1 shows the types, frequencies and percentages of errors committed by the students participate in the study. It can be observed that the students made various grammatical, syntactical, substance, and lexical errors. The total number of errors was 1344 distributed not evenly in the four categories: 570 grammatical errors, 171 syntactical errors, 513 substance errors, and 90 lexical errors. 
Table 1. Frequencies and percentages of errors based on Hubbard et al. (category/subcategory)

\begin{tabular}{cccc}
\hline Category & Subcategories & Frequency & Percentage (\%) \\
\hline & Propositions & 102 & 7.60 \\
& Singular/plural & 132 & 9.82 \\
Grammar & Adjectives & 30 & 2.23 \\
& Tenses & 154 & 11.60 \\
& possessive case & 3 & 0.22 \\
& Relative clauses & 15 & 1.11 \\
& Articles & 134 & 9.82 \\
\hline \multirow{2}{*}{ Syntax } & Nouns and pronouns & 15 & 1.12 \\
& Subject/verb agreement & 150 & 11.16 \\
Substance & Word order & 6 & 0.45 \\
& Capitalization & 120 & 8.92 \\
& Punctuation & 129 & 9.60 \\
Lexical & Spelling & 264 & 19.64 \\
\hline (word choice) & Varied words & 60 & 4.46 \\
\hline Total & Idiom choice or usage & 30 & 2.23 \\
\hline
\end{tabular}

Grammatically, most of the errors (11.60\%) occurred in the subcategory of tenses (continuous verses simple present, present/past perfect verses simple present/past, adding/omitting to be ...etc.), followed by the subcategory of singular/plural nouns $(9.82 \%)$ and the subcategory of articles $(9.82 \%)$. The students had problems deciding which tense to use, distinguishing between countable and uncountable nouns, and determining if an article was needed. Also, the students had some confusion on how to use propositions properly; a preposition links a noun, pronoun, or a phrase and other words in a single sentence and usually indicates the temporal, spatial or logical relationship of the object to the rest of the sentence. There were (7.60\%) proposition errors; for example, using "in" instead of "on" or using "of" instead of "to"...etc. Even though many students avoided writing with adjective phrases, there were some adjective errors (2.23\%); such as putting the noun ahead of the adjective or using an adverb instead of an adjective. Furthermore, many students had problems determining if an article was needed and at times avoided the use of the indefinite articles (a, an) or the definite article (the); the problems with the articles (a, an, the) maybe arise due to direct translation from Arabic, which does not have the equivalent article usage. For example, there were some errors with articles preceding the names of places or the days of the week. The number of possessive case and relative case grammatical errors were low due to the students not attempting to use possessive and relative clauses in their writings.

Syntactically, the students faced difficulties in structuring sentences correctly and made various syntactic errors (subject-verb agreement, verb tenses, and various verb form errors). Specifically, a good number of the students made subject-verb agreement errors (11.2\%). Many students had difficulties applying the correct verbs, picked the wrong verbs for singular/plural subjects, used fragments (part of sentences without verbs or without subjects), and made various tenses errors; for example, some students did not add the "s" to the verb in a sentence with a singular noun or treated the phrase "social media" as a plural phrase and not as a singular phrase. In addition, the students made errors of mixing present/past verbs in the same sentence, which means that the students could not apply the proper tense to the verb. The noun/pronoun errors $(1.12 \%)$ and word order errors $(0.45 \%)$ were not as frequent as the subject-verb agreement types as many students avoided their usage; a pronoun is a word that takes the place of a noun. Some students missed to use a noun or a pronoun when some noun/pronoun was needed while some students misused the human/nonhuman pronoun.

In Substance, most types of errors fell in the spelling subcategory (19.6\%). Many students had spelling problems, which is probably due to the rare use of English vocabulary in everyday conversations and rare English reading as many students professed verbally that they conversed and read mainly in Arabic and not in English. Arab natives usually have problems with same English sound words and with English letters that have different sounds; such as the letter "c" with the "k" sound and deciding the order of two vowels in a word (for example the letters " $\mathrm{i}$ " and "e" in friend); In addition, Arab natives have problems pronouncing English words because they try to imitate Arabic, which is a phonetic language. Therefore, the Arab native students in this study faced problems with spelling words that contained vowels, sound words, unfamiliar words, and words that have the letter "b" or "p" in them. The students made errors in capitalization (8.92\%) by either wrongly capitalizing words or wrongly not capitalizing words. for example, there were errors not capitalizing the words after a period, names of places, or names of the week. Also, the students' made errors in mixing small and capital letter words or starting sentences with small letter words. It is good to note here that Arabic as a language does not distinguish between upper and lower case words. In addition, there was (9.60\%) of errors in punctuations and most of these errors were in missing to use a punctuation symbol when a symbol was needed. Very few students used punctuation symbols other than a period at the end of paragraphs and commas when listing things.

Lexical (word) order is the syntactic arrangement of words in a sentence, clause, or phrase. Some students in this study 
wrote sentences with wrong word order. Lexically, many students made errors due to literal translation from Arabic. The least number of errors fell in this category and this is maybe due to the students using simple sentences and phrases with simple vocabulary and avoiding perceived difficult syntax; for example, a good number of students avoided using adjectives. Sometimes, the students used improper words in their writings; for example, using the word "big" instead of "wide" or using the word "live" instead of "life". The Tables 2-5 list some examples of the errors made in each category/subcategory.

Table 2. Grammatical errors examples

\begin{tabular}{ll}
\hline Grammatical error & Examples (errors are between quotations) \\
\hline Propositions & It will waste "for" your time; Teachers want "of" teach many subjects \\
Singular/plural nouns & There "is" a lot of benefits of the social media programs; divided into "part" \\
Adjectives & Social media have "effective positive"; collapse of banks is "danger" \\
Tenses & Even if we "did" we "will" sit together; family "using" loans; twitter "taken" time to learn \\
Possessive case & The 'life's" work \\
Relative clauses & People "which" get married; To hacking people lives "and" relationships "and" others \\
Articles & It has "a" advantages; now in "the" many countries; media has "a" side affects \\
\hline
\end{tabular}

Table 3. Syntactic errors examples

\begin{tabular}{ll}
\hline Syntax errors & Examples (errors are between quotations) \\
\hline $\begin{array}{l}\text { Nouns/pronouns } \\
\text { Subject/verb agreement }\end{array}$ & $\begin{array}{l}\text { Social media "it" has negative effects; "These" marriage custom is wrong; in "this" days } \\
\text { whatApp and Twitter "is" important; he "look"; social media "have"; people will "have" } \\
\text { different customs since old times; }\end{array}$ \\
Word order & $\begin{array}{l}\text { When finished go on social media "done your work last"; negative effect like in SnapChat } \\
\text { no private life; he sent always; he "went often" to local banks }\end{array}$ \\
\hline
\end{tabular}

Table 4. Substance errors examples

\begin{tabular}{ll}
\hline Substance errors & Examples (errors are between quotations) \\
\hline Capitalization & ...and lazy. "finally", we should; negative and "Positive" things;"facebook and snapchat"; the \\
& god \\
not using any punctuation example: $\quad$ Your family but also others \\
using comma instead of period example: in real world, In the home;
\end{tabular}

Table 5. Lexical errors examples

\begin{tabular}{ll}
\hline lexical error & Examples of the errors \\
\hline Using "live" instead of "life" & my personal "live" \\
Using "follow" instead of "knowledge" & Children use media without "follow" of their parents \\
Using "popular" instead of "famous" & Many "popular" people \\
Using "big" instead of "widely" & Social media in Saudi Arabia is very "big" used \\
Using "devil" instead of "bad" & Social media can be used for good purposes and for "devil" things \\
Using "light" instead of "weak" & Relationship among relatives became "light" \\
\hline
\end{tabular}

Finally, this research does not investigate the causes of errors since the researcher only has known the students while teaching at the university and she is not familiar with their English language background. Also, the study does not divulge into the grammar, vocabulary, or any other language skill except the students' writings abilities. More importantly, this study was conducted on female students in one department/university and thus the results only reflect those writing skills of this limited investigated sample and cannot be necessarily generalized to all male/female students in the university or to other students in other universities in the kingdom of Saudi Arabia. Thus, a more extensive study that includes students from various faculties and from various universities is needed and it should give a clearer picture of the shortcomings in the writing skills of Saudi students.

\section{Conclusion}

This study set out to investigate and categorize writing errors made by university female students majoring in English studies. The students took a quiz to write approximately one page about each one of three topics. Based on the findings, it can be concluded that the students committed four main categorized errors: grammar, syntax, substance, and lexical errors and the topic title did not make any significant variation of the frequency of committed errors. Also, the findings have some pedagogical implications and reveal the most frequent types of errors made by the students: spelling, subject-verb agreement, tenses, singular/plural nouns, and articles. The students writing errors were caused probably by lack of conversation in the English language, rare reading in English, and from interference of the Arabic language. Therefore, it can be recommended to improve courses syllabuses and add various teaching strategies and methods that target to improve students' writing skills by attributing some causes of these errors and try to solve the shortcomings. 


\section{References}

Abdullah, A. K., \& Ali, A. S. (2000). Writing Errors: A study of the writing ability of the Arab learners of academic English and Arabic at University. Language, Culture, Curriculum, 13(2), 174-183. https://doi.org/10.1080/07908310008666597

AbiSamra, N. (2003). An analysis of errors in Arabic speakers' English writing. In Mourtaga, K. (Ed.). Investigating writing problems among Palestinian students studying English as a foreign language. Unpublished doctoral dissertation.

Al-Bauinain, H. (2007). Researching types and causes of errors in Arabic speakers' writings. In Madraj, S., Jindli, A. and Salami, A. (Eds). Research in ELT Context, 195-224.

Alkhresheh, M. (2010). Interlingual interference in the English language word order structure of Arab EFL learners. European Journal of Social Sciences, 16(1), 106-113.

Ancker, W. (2000). Forum English Teaching, 38(4), 20-25.

Burt, M., \& Kiparsky, C. (1972). The Gooficon: A repair manual for English. Rowley, Newberry House.

Corder, S. P. (1967). The significance of learners' errors. Reprinted in J. C. Richards (ed.) (1984). Error analysis: Perspectives on second language acquisition, London: Longman, 19-27.

Corder, S. P. (1974). Error Analysis. In J. P. B. Allen and S. Pit Corder (eds.) Techniques in Applied Linguistics (The Edinburgh Course in Applied Linguistics:3). London: Oxford University Press (Language and Language Learning), 122-154.

Diab, N. (1996). The transfer of Arabic in the English writings of Lebanese students. Retrieved Jan. 5, 2003 from http://lael.pucsp.br/especialist/181diab.ps.pdf

Dulay, H., \& Burt, M. (1972). You can't learn without goofing: Analysis of children's second language errors. In Richards, J. (1984) (op cit).

Dulay, H., Burt, M., \& Krashen, S. (1982). Language Two. Oxford University press.

Ellis, R. (1997). Second language acquisition. Oxford: Oxford University Press.

Farooq, M. U. (1998). Contrastive and error analysis based teaching strategies. Aichi Women's Junior CollegeRetrieved December 30, 2003 from http://www.cels.bham.ac.uk/resources/essays/farooq2.pdf

Gass, S., \& Selinker, L. (2001). Second language acquisition: an introductory course. Mahwah, NJ: LEA, chapter 3.2.

Habash, Z. (1982). Common Errors In The Use of English Prepositions In The Written Work Of UNRWA Students At The End Of The Preparatory Cycle In The Jerusalem Area. Retrieved Jan. 2, 2003 from http://www.zeinab-habash.ws/education/books/master.pdf

Hubbard, P., Jones, H., Thornton, B., \& Wheeler, R. (1996). A Training Course for TEFL. Oxford: Oxford University Press.

James, K. (1998). Errors in language learning and use: Exploring errors analysis. London: Longman.

Jarvis, S. (2002). Topic continuity in L2 English article use. Studies in second language acquisition, 24, $387-418$. https://doi.org/10.1017/s0272263102003029

Ridha, N. (2012). The Effect of EFL Learners' Mother Tongue on their Writings in English: An Error Analysis Study. Journal of the College of Arts (University of Basrah), 60, 22-45.

Taylor, B. P. (1975). The use of overgeneralization and transfer learning strategies by elementary and intermediate students of ESL. Language Learning, 25, 73-107. https://doi.org/10.1111/j.1467-1770.1975.tb00110.x

Vahdatinejad, S. (2008). Students' error analysis and attitude towards teacher feedback using a selected software: a case study. Unpublished Masters thesis. Universiti Kebangsaan Malaysia, Bangi.

\section{Copyrights}

Copyright for this article is retained by the author(s), with first publication rights granted to the journal.

This is an open-access article distributed under the terms and conditions of the Creative Commons Attribution license which permits unrestricted use, distribution, and reproduction in any medium, provided the original work is properly cited. 